\title{
Una vision del exilio republicano en Gran Bretaña : Perico en Londres, de Esteban Salazar Chapela
}

Francisca Montiel rayo

\section{Citer ce document / Cite this document :}

Montiel rayo Francisca. Una vision del exilio republicano en Gran Bretaña : Perico en Londres, de Esteban Salazar Chapela. In: Exils et migrations ibériques au XXe siècle, $n^{\circ} 6,1999.60$ ans d'exil républicain : des écrivains espagnols entre mémoire et oubli. pp. 209-226;

doi : https://doi.org/10.3406/emixx.1999.1014

https://www.persee.fr/doc/emixx_1245-2300_1999_num_2_6_1014

Fichier pdf généré le 28/08/2018 


\title{
Una visión del exilio republicano en Gran Bretaña : Perico en Londres, de Esteban Salazar Chapela
}

\author{
Francisca Montiel Rayo \\ GEXEL (Universitat Autònoma de Barcelona)
}

En febrero de 1939, ante la inminencia del reconocimiento oficial de Franco por parte del gobierno británico, el escritor malagueño Esteban Salazar Chapela abandonó la legación de la República Española en Escocia, en cuya sede de Glasgow había desempeñado el cargo de cónsul desde junio de 1937. Antes de partir hacia Londres, escribía a su amigo Guillermo de Torre la última de las cartas que había de remitirle desde esa ciudad. En ella, le expresaba su dolor de republicano vencido, "saltando sobre el problema personal que [confesaba] esta situación me plantea" :

Tengo el corazón lleno con la situación de tanto refugiado en Francia, muchos de los cuales tendrán que regresar a territorio faccioso, seguros de recibir terribles penas, antes que sufrir la miseria a que los condena Francia - la Francia del Frente Popular. Ahora a ver si alguna vez reconquistamos nuestra patria perdida. Aquello será una sacristía injerta en cuartel, asentada sobre un pueblo hambriento, tributario a la vez de Alemania e Italia - y Francia e Inglaterra ${ }^{2}$.

Salazar Chapela no ignoraba las privilegiadas circunstancias en las que se iniciaba su exilio. Su presencia en Gran Bretaña durante el último año y medio de guerra civil le situó a salvo de las cárceles españolas y de la reclusión en los campos de concentración franceses, a los que aludía en la carta citada. En territorio británico pudo beneficiarse además de su condición de cónyuge de una súbdita inglesa - con quien había contraído matrimonio civil en 1933 -, y contó también con la ayuda de su familia política, a la que acudió al llegar a Londres.

\footnotetext{
${ }^{1}$ Carta de Salazar Chapela a Guillermo de Torre fechada en Glasgow el 26 de febrero de 1939 (ms. 22830-10 (26), Biblioteca Nacional de España, Madrid).

2 Ibidem.
} 
Aunque no hubo de preocuparse, por tanto, de solventar las necesidades más perentorias, sí sintió desde un primer momento el vacío que se abría ante su futuro. Salvada, siquiera parcialmente, "la desorientación mía en los primeros meses del nuevo estado ${ }^{3}$, tiempo que dedicó sobre todo a recabar noticias sobre los amigos que habían quedado dispersos por la ya entonces amplia geografía del destierro -"intelectuales que no caben, puesto que son intelectuales, en $\mathrm{cl}$ "Imperio ${ }^{4 "-}$, se propuso la reanudación de sus actividades profesionales, forzosamente interrumpidas durante el coyuntural paréntesis diplomático. Tras considerar diversos proyectos, se interesó finalmente por la elaboración de un ensayo en el que pensaba estudiar "un tesoro de cosas españolas, algunas tan curiosas que no sé que existan en Madrid", que había encontrado en la biblioteca del Museo Británico.

El devenir de la guerra mundial y las ocupaciones en las que se empleó durante ese tiempo ${ }^{6}$ fueron demorando el trabajo. Sin embargo, nada impidió que Salazar Chapela mantuviera permanente contacto con el colectivo republicano refugiado en Gran Bretaña, con el que participó en diversas actividades. Esas experiencias le ayudaron a reconsiderar su proyecto, de suerte que el ensayo histórico previsto acabó convirtiéndose en una novela sobre el exilio republicano en Gran Bretaña, cuya finalización alcanzó a principios de 1946. Confiado en la ayuda de sus compatriotas transterrados en América, donde era lógicamente más fácil acceder al mundo editorial, envió el original a Guillermo de Torre. Gracias a él y a Francisco Ayala

${ }^{3}$ Carta de Salazar Chapela a Guillermo de Torre fechada en Londres el 18 de agosto de 1939 (ms. 22830-10 (27), Biblioteca Nacional de España, Madrid).

${ }^{4}$ Ibidem.

${ }^{5}$ Carta de Salazar Chapela a Guillermo de Torre fechada en Londres el 30 de agosto de 1939 (ms. 22830-10 (28), Biblioteca Nacional de España, Madrid). El material bibliográfico al que se refería Salazar Chapela estaba formado por diversas colecciones de revistas editadas en Gran Bretaña, parte de las cuales fue utilizada posteriormente por el también exiliado Vicente Lloréns para la elaboración de su ensayo Liberales y románticos: Una emigración española en Inglaterra (1823-1834) (México, Fondo de Cultura Económica-Nuevo Mundo (Publicaciones de la Nueva Revista de Filología Hispánica-El Colegio de México), 1954,382 p.).

${ }^{6}$ Como otros refugiados españoles, Salazar Chapela escribió crónicas para la BBC. En 1941 fue nombrado lector de español en Cambridge, puesto que desempeñó durante dos cursos. Posteriormente se ocupó de la creación del Instituto Español de Londres, del que fue, desde su fundación en enero de 1944, secretario y gustoso peón de brega, como solía repetir. 
-colaboradores ambos de la bonaerense Editorial Losada -, la narración, que tituló Perico en Londres ${ }^{7}$, se publicó dieciséis años después de que viera la luz su primera novela ${ }^{8}$.

Pero si entonces describió con entusiasmo el clima previo y la proclamación de la II República, ahora abordaba un asunto poco feliz, aunque igualmente vinculado a su vida y a la historia de España. En Perico en Londres compuso Salazar Chapela una nueva novela de la experiencia como lo fue el resto de su producción narrativa ${ }^{9}$-, en la que vertió elementos autobiográficos, incorporó a personas conocidas, lecturas, debates públicos, reflexiones y cuantos componentes configuran toda experiencia vital. Los protagonistas del destierro en Gran Bretaña, sus vicisitudes y sus principales preocupaciones aparecen así fielmente reflejados en esta crónica, considerada en el momento de su publicación "la primera novela seria de esta lucha de adaptación o inadaptación ${ }^{10}$ que hubieron de librar los exiliados republicanos.

\section{Historia e intrahistoria del exilio}

Para abordar el tema, Salazar Chapela situó la narración en los primeros años del destierro, los comprendidos entre el verano de 1939 y enero de 1943. Obviamente, durante ese tiempo los refugiados padecieron las mayores dificultades y vivieron en continuo estado de incertidumbre. Pero la

${ }^{7}$ Esteban Salazar Chapela, Perico en Londres, Buenos Aires, Editorial Losada (Novelistas de España y de América), 1947, 293 p.

${ }^{8}$ Pero sin hijos (Madrid, Renacimiento, 1931, 306 p.) constituyó una revelación de las dotes novelísticas de Salazar Chapela, confirmadas, al parecer de su amigo Antonio Espina, con su segunda obra: "En este gran libro que es Perico en Londres, nos muestra el autor cuán fecundo ha sido su silencio de emigrado" ("Crónica de Vidas y Exilio. Perico en Londres", España Republicana, Buenos Aires (sábado, 14 de agosto de 1948).

${ }^{9}$ He tratado sobre esta característica de la obra de Salazar Chapela en la "Introducción" a mi edición de su novela inédita En aquella Valencia (Sant Cugat del Vallès, GEXEL-Cop d'Idees (Ipanema, 1), 1995, p. 9-26) y en el artículo "La narrativa exiliada de Ésteban Salazar Chapela" (Eugenio Pérez Alcalá (ed.), La literatura del exilio español de 1939. Andújar, Excmo. Ayuntamiento [en prensa]).

${ }^{10}$ E.G.L., "Esteban Salazar Chapela. Perico en Londres", Revista Hispánica Moderna, New York, XIII, 1-2 (enero-abril de 1947), p. 62. 
proximidad de la guerra civil y la firmeza de sus convicciones republicanas, reforzadas por una derrota que no podían ver sino como injusta, impidieron que observaran su situación como un mero problema personal ; se sintieron parte de un colectivo que permaneció, al menos durante ese período, bastante cohesionado. Los españoles residentes en Londres - donde se sitúa la novela -mantuvieron constante comunicación entre ellos, como también lo hicieron con quienes se hallaban radicados en otras localidades de Gran Bretaña. Aunque con mayores dificultades, intercambiaron asimismo noticias con los compatriotas que se encontraban en Francia o en América, y con aquéllos que no habían logrado salir de España. Permanecía viva la esperanza de un pronto y común regreso.

El inicio de la guerra mundial había alimentado sus expectativas, porque, como afirma un personaje de Perico en Londres, "la situación española estaba engastada -"ésta era la palabra : engastada"- en la situación europea" [p. 49]. Consecuentemente, el desarrollo del conflicto recorre los tres actos y el telón provisional en los que, al modo dramático, se estructura la novela. Al mismo tiempo, Salazar Chapela desarrolla un segundo hilo argumental, por el que se informa al lector sobre la marcha del estudio que Perico está elaborando. Se trata del ensayo frustrado que Salazar Chapela había proyectado al emprender el destierro, porque como éste, Perico, "un arquitecto en desgracia, es decir desterrado y ocioso" [p. 285], se plantea qué puede hacer mientras espera. El sueño que le sobresalta una noche, después de haber asistido a una reunión con sus compatriotas en la que se hallaba presente también Dora, una joven inglesa por la que se siente atraído, revela la disyuntiva en la que se debatieron los expatriados : optar por la salvación personal o luchar por la redención colectiva ${ }^{11}$. En su mente se superponen dos cuadros. El primero muestra una multitud de compatriotas que avanza hacia él bajo una lluvia torrencial para pedirle algo que Perico ignora y que, de acuerdo con el valor simbólico del sueño, interpreta como un impermeable o un paraguas. Sobrecogido por la angustia de la visión, Perico piensa que no podrá ayudarles - "él no tenía más que un paraguas. Él no

11 Para Eduardo Godoy Gallardo "la salvación personal y colectiva en la búsqueda de una identidad" es el tema central de Perico en Londres; de La raíz rota, de Arturo Barea; de Habitación para hombre solo, de Segundo Serrano Poncela, y de El cortejo, de Simón Otaola ("La búsqueda de una identidad perdida y de una nueva morada en la novela del exilio republicano", Hora actual de la novela hispánica. Valparaíso, Ediciones Universitarias de Valparaíso de la Universidad Católica de Valparaíso (Universidad: Cátedra), 1994, p. 147). 
tenía más que un impermeable" [p. 63]. Esta frustrante sensación de impotencia se atenúa cuando repara en el segundo cuadro, en el que ve a Dora. Ya en estado de vigilia, Perico pensará que tiene
"una misión que cumplir" [...]; su destino de desterrado era hurgar con amor, con el amor dolorido de un proscrito, en los entresijos de la Historia [p. 77].

Emprenderá entonces la elaboración del mencionado estudio, con el que saciaria "una curiosidad [...] vital y caliente, casi una necesidad" [p. 61-2] : la sed de Historia que le había acometido desde su llegada a Inglaterra. Era ésta también la mejor forma que veía de comprometerse con el colectivo exiliado, porque el suyo iba a ser "el libro de su destierro, nuestro libro universal del destierro" [p. 66]. Con él
pretendería dar ante todo a los emigrados de hoy conciencia de quiénes eran, de dónde venían, hacia dónde iban... Era probable que la mayoría lo ignorara [...]. Tenían todos ellos, en cuanto emigrados y perseguidos, en cuanto españoles "de otra opinión" o disidentes, un pretérito claro, un abolengo nobilísimo [p. 69].

Por ello, el ensayo se iniciaría a mediados del siglo XVI, cuando quinientos soldados españoles llegaron a las islas británicas, donde se pusieron al servicio del rey :
Al fin y al cabo ¿no era su obra una procesión, un desfile penitencial de españoles, donde todos vestian el pardo sayal del peregrino, llevaban en sus mochilas el duro mendrugo del destierro y portaban sobre los ojos la melancolía de la añoranza ? [p. 73]

Mientras Perico va trazando la historia de las emigraciones españolas en Gran Bretaña, el narrador nos muestra el presente del último exilio, el que Salazar Chapela estaba viviendo. Para ofrecernos su visión del mismo, se sirvió de un nutrido personaje coral en el que integró a más de un centenar de seres, a través de los cuales descubrimos la intrahistoria del destierro. Se trata de un grupo menos numeroso que el que acudió a otros países de acogida, y también más selecto, pues está mayoritariamente compuesto por diplomáticos, políticos, científicos e intelectuales. Buena parte de los caracteres de la novela oculta su verdadera identidad bajo pseudónimos 
transparentes, procedimiento que ha permitido hablar de Perico en Londres como de una novela en clave ${ }^{12}$. Sin embargo, no siempre resulta fácil reconocer a quienes los inspiraron ; en numerosos casos, como acostumbró a hacer en toda su obra, Salazar Chapela efectuó una amalgama de rasgos procedentes de distintas personas, algunas de las cuales no tuvieron proyección pública.

Perico Mejía es, como se ha afirmado reiteradamente, el alter ego de su autor, pero no el protagonista de la novela, función que encarna todo el colectivo exiliado. En realidad, actúa como un personaje imán que atrae hacia sí a los demás republicanos y que posee también amigos y relaciones entre la población británica, no en vano "conocía a todo el mundo" [p. 39]. Respecto a la impronta autobiográfica que recibe en su concepción, cabe destacar la importante misión que Salazar Chapela le concedió al convertirlo en portavoz de su pensamiento. Perico es un intelectual de firmes convicciones liberales y de un acusado europeísmo que se siente identificado con la mentalidad dieciochesca. Al igual que le sucediera a su creador, intenta conciliar en el destierro su racional rechazo de cualquier localismo con el dolor y la nostalgia que siente por la patria perdida.

Por las páginas de Perico en Londres transita por primer vez Sebastián Escobedo, personaje que habría de convertirse en alter ego de Salazar Chapela en sus narraciones posteriores. En ésta se menciona su condición de excónsul en Glasgow, su actual dedicación académica en Cambridge y su participación en los preparativos del Instituto Español. Sin embargo, el autor no profundiza en este personaje porque el análisis individual, el enfoque existencial de la experiencia del exilio lo realiza a través de Perico y de otros dos caracteres, a los que dotó también de distintos rasgos de su propia personalidad. El exdiputado a Cortes Casto Palencia es un ser hasta cierto punto ridículo que comparte con él su afición por la poesía, inclinación que Salazar Chapela interpreta en el contexto del destierro como una forma de evasión. Sus efusiones líricas y su carácter enamoradizo contrastan con el prosaísmo de su vida, marcada por la envidia, los enfermizos celos de su esposa y, desde su llegada a Londres - donde malvive como buenamente puede -, por las preocupaciones económicas. En Carlos Pérez, el personaje más politizado de la novela, representó Salazar Chapela la coherencia

\footnotetext{
12 "Era curiosa, era una novela en clave [...]. El tal Perico era él mismo, y otros personajes eran también gentes de la época..." (Enriqueta Antolín, Ayala sin olvidos. Madrid, Espasa Calpe (Memoria de la vida), 1993, p. 107-108).
} 
ideológica y el activismo político. Convencido de la necesidad de que los exiliados se organicen, se erige en líder del colectivo, una misión que, si bien le reporta la complacencia del deber cumplido, no conseguirá mitigar su profunda insatisfacción vital. Porque como exiliado, siente un malestar inherente a su condición que sólo halla consuelo en la relación que mantiene con Irene, a quien declara su amor para desaparecer después del escenario de la novela. Perico Mejía, Carlos Pérez y Casto Palencia personifican, en suma, las diferentes actitudes con que cualquier individuo puede responder ante la experiencia del destierro : el análisis intelectual, la búsqueda de una solución personal y el compromiso político. Tres posturas que, sin duda, también se confundieron en la mente y en el espíritu de Salazar Chapela.

La colonia exiliada en Londres se reúne periódicamente en casas o en locales públicos para compartir sentimientos y opiniones. Acudir al restaurante español "Madrid", donde "había un día a la semana, en una habitación interior que comunicaba con la cocina, una comida de refugiados" [p. 184], les ayuda a acortar la distancia que los separa de la patria, porque, al decir de Carlos Pérez, "una buena comida española fortalece nuestra personalidad peninsular, que yo creo que no debemos perder" [p. 55]. Sólo él $y$, ocasionalmente, Perico visitan el Queen's, a cuya tertulia se acercan habitualmente los exiliados que no residen en Londres; esto es, los que trabajan en las afueras, viven lejos o vuelven después de navegar durante meses como marinos mercantes. La visión del exilio que el autor nos ofrece a través de los refugiados en la capital se amplía con nuevas experiencias personales y diferentes puntos de vista, acentuándose así la mirada caleidoscópica que toda crónica exige ${ }^{13}$. De esta manera Salazar Chapela consigue reproducir con bastante fidelidad la realidad vivida por los republicanos residentes en Gran Bretaña, aunque sin caer en la amargura y el

${ }^{13}$ Mediante las conversaciones introduce Salazar Chapela noticias sobre algunos exiliados cuyas vidas no puede seguir por razones obvias, procedimiento que ha servido para señalar el "carácter de tertulia de café" de la novela (R. Troyano de los Ríos, "Salazar Chapela, Esteban, Perico en Londres, Editorial Losada, Buenos Aires, 1947", Asomante, Puerto Rico, 1 (enero-marzo 1948), p. 78). Por su parte, Eugenio de Nora la ha calificado de "reportaje trivial, animado por anécdotas que no llegan a estructurarse en argumento" ( $L a$ novela española contemporánea (1898-1967), vol. II, Madrid, Gredos (Biblioteca Románica Hispánica: Estudios y Ensayos, 41), 1968, 2a. ed., p. 421). 
desgarro que recorre otras creaciones sobre la diáspora ${ }^{14}$. El humor que destila la novela, poco apropiado a priori por su contenido, no procede, obviamente, de la comicidad de lo contado, sino de una deliberada actitud del narrador, quien en Perico en Londres, como en su propia vida y en toda su obra, quiso mitigar cualquier amago de pesimismo con este rasgo de su carácter ${ }^{15}$.

\section{Nuevos heterodoxos en Gran Bretaña}

Al fin y al cabo, Salazar Chapela compuso una obra literaria, aunque ensayara en ella la siempre compleja aleación de rigor histórico y libertad creadora. Un propósito que contó en el caso de Perico en Londres con una dificultad añadida, la interpolación de fragmentos procedentes de la investigación que lleva a cabo el personaje que da título a la obra. Éstos imprimen a la narración una inusual morosidad que ha suscitado los reparos de la crítica, al considerarla un híbrido entre el ensayo y la novela ${ }^{16}$. Sin embargo, Salazar Chapela no realizó un aprovechamiento gratuito de los materiales de que disponía. Porque el conocimiento de las emigraciones

14 Es el caso, por ejemplo, de Virgilio Botella Pastor, cuya narrativa ha sido estudiada por Pablo Gil Casado, quien cita lo que constituye una declaración de intenciones del autor, bien alejadas de las que movieron a Salazar Chapela a componer Perico en Londres: "Quiero dar forma escrita al patetismo colectivo, a clianto tiene de profundamente humano ese constante entrecruce de destinos, al devenir confuso y múltiple de la muchedumbre exiliada en su vida especial" ("Las novelas de Virgilio Botella Pastor: del éxodo y del llanto", Cuadernos Americanos, México, 5 (septiembre-octubre de 1980), p. 238).

15 Para Soldevila Durante "la zumba del narrador surge del horror al melodrama que la historia contada con seriedad hacía difícil de evitar" (La novela española desde 1936. Madrid, Alhambra (Historia de la literatura actual, II), 1980, p. 70). Max Aub consideró que Salazar Chapela "supo unir con bien su amargura de emigrado con su auténtica gracia andaluza" (Manual de historia de la literatura española. Madrid, Akal (Textos), 1974, 2 a. ed., p. 528). Por su parte, Francisco Ayala la calificó de novela "escrita con gracia [...]. La crítica dijo que se notaba la influencia del humor inglés, una completa estupidez, qué humor inglés... Era su humor, el suyo propio" (Enriqueta Antolín, Ayala sin olvidos, ob. cit, p. 107108).

${ }^{16}$ José Ramón Marra-López insistió en señalar el defecto que supone este "ensayo injertado en la novela", pues, a su entender, perjudica una narración en la que encuentra destacados aciertos (Narrativa española fuera de España (1939-1961). Madrid, Guadarrama (Crítica y Ensayo, 39), 1963, p. 168-169). 
políticas ocurridas a lo largo de la historia de España le permitió destacar, por comparación, los aspectos diferenciales de la última, la más numerosa de cuantas se habían producido hasta entonces. Los expatriados en 1939, como había sucedido durante cinco siglos, no podían vivir en España por sus discrepancias ideológicas :

En los siglos XVI y XVII los llamaron protestantes, el XVIII enciclopedistas, en el XIX constitucionales y liberales. Ahora en el XX se llaman republicanos, aunque también es verdad que se pueden llamar antifascistas, pues son ambas cosas [p. 65].

Pero, contrariamente a lo que les sucedió a sus antepasados, a sus primeros padres, como Perico los llama con orgullo, estos nuevos heterodoxos han sido acogidos por Gran Bretaña - un país tradicionalmente hospitalario para con los disidentes españoles - en las peores circunstancias de su historia. Porque si en los siglos XVI y XIX les concedieron pensiones, ahora no poseen nada, ni pasaporte, sólo - afirma Palencia - "llevamos en el bolsillo nuestro Certificate of Registration, que es algo así como el título de nuestra carrera" [p. 115]. Y es que, como expresa Perico,

por mucho que lo disimule la educación y el decoro, en el fondo no les somos simpáticos. Equivocación supina. Ni un reformista del XVI ni un liberal del XIX hicieron tanto por Inglaterra como un republicano del XX. ¡Ahí es nada abrirles los ojos con nuestra propia sangre, advertirles del cataclismo, darles tiempo con nuestra resistencia para que se prepararan al menos! [p. 68-69]

En consecuencia, el país suscita sentimientos encontrados entre los emigrados. Por un lado, muestran el natural agradecimiento por el asilo recibido, pero, como republicanos, no pueden olvidar la participación de Gran Bretaña en el Comité de No Intervención, ni aprobar las relaciones que el gobierno británico ha establecido con la España de Franco ${ }^{17}$. Al igual que

${ }^{17}$ Sobre la política británica puede consultarse el libro de Enrique Moradiellos La perfídia de Albión. El gobierno británico y la guerra civil española (Madrid, Siglo XXI de España Editores, 1996, 408 p.). Para conocer el tratamiento que la prensa inglesa dio a las cuestiones españolas durante la segunda guerra mundial resulta de gran interés el trabajo de Josep María Torres i Pladellorens, Espanya $i$ la Segona Guerra Mundial a "The Times" (1939-1945). Recopilació de les principals noticies publicades al diari "The Times" de 
sucediera durante la guerra civil, deben distinguir la política de estado en relación con la República española - fatalmente encarnada ahora en las restricciones de entrada de refugiados que han sido establecidas -, de la solidaridad ofrecida por la población británica, representada en la novela por el escocés Mackay. Gracias a sus gestiones y a su dinero - trasunto del esfuerzo real que llevaron a cabo grupos de población británicos y cuáqueros durante los primeros tiempos del destierro -, Don Bernardo - exarchivero municipal de Málaga - y su hija Irene han podido salir del campo de Argelès y han logrado sentir una gratificante sensación de seguridad, una "inyección de esperanza" [p. 8] al pisar suelo británico. Acomodados provisionalmente en casa de los Alington - un matrimonio que nunca había sentido simpatía por los republicanos pero que accede a hospedar a dos refugiados españoles por la insistencia de sus hijos, Dora y John -, contribuirán con su ejemplo, como sus compatriotas, a modificar la opinión que una parte de la población británica tiene de ellos, porque, según afirma Carlos Pérez,

nos conviene muchísimo dar en este país la medida de lo que somos. Hay que deshacer la fama de salvajes que la propaganda fascista nos dio a los republicanos durante la guerra [p. 82].

En efecto, algunos de los prejuicios y de los tópicos que pesan sobre la población española remiten tras el party que lady Alington celebra en su casa para que sus huéspedes no se sientan tan solos. La señora, que no ha sido respaldada en su iniciativa por su marido, se muestra encantada, pues

no todos los días podía lady Alington congregar en su casa aves de plumaje tan vario, aves además tan respetuosas y amables, cuyos trinos no eran por otra parte tan estentóreos como presumiera sir Percy. Incluso comenzaba a pensar lady Alington que su marido se estaba perdiendo "algo" [p. 47].

Pero la dignidad republicana de don Bernardo y de su hija les impide prolongar más allá de lo prudente la tranquilidad y el ocio que sus anfitriones les proporcionan, por lo que deciden buscar trabajo. Las posibilidades de colocación para los españoles no son, sin embargo, ni abundantes ni 
adecuadas a su categoría profesional, que ven rebajada de manera ostensible al tener que desempeñar puestos no cualificados. "La dificultad estaba en el idioma" [p. 106], pensaba Carlos Pérez mientras oía hablar con despecho a Palencia, quien, como Callejo (Luis Gabriel Portillo) - exauxiliar de la Universidad de Salamanca - estaba cavando trincheras cerca de Oxford. El coronel Requena empaquetaba específicos en el sótano de una farmacia ; don Augusto Miró de Santaella (José Rodríguez Olazábal), abogado y elocuente orador que había ocupado el cargo de presidente de la Audiencia de Alicante, trabajaba en unas excavaciones en el Támesis; otros hacían lo propio en granjas, en fábricas o en la construcción de refugios. Dichas condiciones laborales y el temor a las consecuencias de una posible intervención española en el conflicto europeo llevan a numerosos exiliados en Gran Bretaña a considerar el país como un lugar de tránsito, que abandonan en cuanto pueden conseguir el visado para viajar a Hispanoamérica, donde, por las noticias que les llegan, esperan contar con mejores condiciones de vida.

La fundación de The Information Centre, una agencia periodística que distribuía artículos en español para la prensa hispanoamericana ${ }^{18}$, les permitió a muchos de ellos liberarse de los pesados trabajos que venían realizando. Casto Palencia y Callejo fueron los primeros en dejar el pico para tomar la pluma. Les siguieron,

en enjambre descomunal : diplomáticos e ingenieros, abogados y boticarios, médicos y burócratas, incluso un chico entusiasta, despejadísimo, muy leído en cuestiones sociales, todos, estimulados por la necesidad, probaron fortuna y vieron con satisfacción y sorpresa que sí, que sabían escribir... [p. 106]

Pero, más que sus dotes periodísticas, los responsables de la empresa valoraron en ellos el dominio de los temas que siempre demostraban, a pesar de que se les hubiera prohibido escribir sobre España. Para Palencia, las razones de esta superioridad eran evidentes :

Es que los españoles sabemos de esta guerra más que nadie en el mundo; desde luego, más que los ingleses. ¿Qué ignoramos nosotros, especialmente del fascismo ? Nada. Al fascis-

${ }^{18}$ A través de esa agencia recrea Salazar Chapela el Servicio para Hispanoamérica de la BBC, cuyas emisiones se ampliaron notablemente al iniciarse la guerra mundial. 
mo lo hemos visto nacer en teoría, en "literatura"; luego lo vimos en su clara "dialéctica de las pistolas"; por último se nos impuso en todas sus proporciones horribles con "el glorioso alzamiento nacional" y en el curso de nuestra guerra. Aquí nadie sabía nada de esto [p. 115].

Los exiliados estaban realizando, como reconocía Pérez con orgullo, "una formidable contribution al esfuerzo de guerra" [p. 116], tanto en fábricas y talleres como en las labores de propaganda. Especialmente en estas últimas, pues todos los escritores residentes en Londres fueron requeridos por Emilio López Ortiz para colaborar en The Atlantic Press, la agencia que había creado con el apoyo económico de varias embajadas y legaciones hispanoamericanas ${ }^{19}$. Otro español, Plácido Lara (Angel Ara), considerado por los refugiados "príncipe de la emigración española" [p. 175] porque contaba con lo que todos soñaban, un sueldo fijo, empleaba también a sus compatriotas en las comedias radiofónicas que dirigía. Con estas meritorias actividades, los españoles iban adquiriendo el reconocimiento como colectivo que Gran Bretaña les había negado hasta entonces. A él contribuyeron notablemente los científicos Río Hortega, Dávila (Arturo Duperier), Vélez Gómez (Federico Duran-Jordà) y el doctor Ripoll (Josep Trueta), y, en el ámbito artístico, el músico Gerardo Xuclá (Roberto Gerhard i Ottenwaelder).

Los cambios operados en la política inglcsa beneficiaron también al colectivo español. La llegada de Churchill les ayudó a superar el triste recuerdo que había dejado en sus mentes la actuación de Chamberlain durante la guerra civil. El nuevo primer ministro fue el artífice de una de las principales satisfacciones que sintieron los españoles, en tanto republicanos, en el país que les acogía. Porque en un discurso radiado, Churchill alentó a la población británica a resistir los embates de la guerra, convencido como estaba de que "lucharían y resistirían... como los hombres de Barcelona. Jamás se rendirían" [p. 201]. Sus palabras fueron recibidas con júbilo por Perico. Creía que, con ese emocionado recuerdo,

¡por fin un primer ministro británico ponía una corona de laurel sobre la épica de la lucha desigual y terrible y por fin se hacía justicia (al menos, retóricamente), desde la cumbre de

19 Alude Salazar Chapela a The Atlantic Pacific Press Agency, servicio que dirigio durante 1941 y 1942 el periodista sevillano Manuel Chaves Nogales. 
Britania en peligro, al cuadro fenoménico de un país en pie, resistiendo casi tres años inerme, bombardeado, sin víveres! [...] ¡Por fin se hundían verticales diez años de una política claudicante, estúpidamente aviesa, antipáticamente torpe, que había castigado un día y otro el orgullo natural, tradicional del gran pueblo! [p. 201-202]

Desde el punto de vista de Ricardo Parejo, un tipógrafo procedente de España que "contaba espeluznantes relatos" [p. 205], la emigración, acomodada a las mejoras que había ido logrando no sin esfuerzo, estaba cayendo en el aburguesamiento. Por razones económicas, había fracasado la creación de una revista de información literaria y política impulsada por Carlos Pérez. Mayor fortuna había tenido su segunda iniciativa, la formación de un coro artístico compuesto por jóvenes españoles que contó con la dirección del músico Manuel Filomeno (Manuel Lazareno). Aunque sus primeras actuaciones habían resultado todo un éxito, Pérez creía que aquello era insuficiente :

Había que hacer algo más. Había que hacer una cosa que congregase a los emigrados y mantuviera vivo el fuego sagrado de la República [p. 204].

La inesperada presencia de Negrín en Gran Bretaña fue un estímulo para él, que consideraba que, aunque la prensa no se hubiera hecho eco de ella apenas, debía ser interpretada del mismo modo que

la llegada a Londres de De Gaulle, de Benes y de los núcleos y retazos de los gobiernos de Polonia, Noruega, Holanda, Bélgica y Luxemburgo. Al fin y al cabo ¿en qué se diferenciaba el legítimo gobierno español de los demás gobiernos de países ocupados por el nazismo ? En nada. En el tiempo acaso [p. 204].

Con la ayuda de Parejo, Pérez acometió la puesta en marcha de un nuevo y ambicioso empeño, un local en el que pudieran reunirse los emigrados. Allí debatirían sobre temas de interés común y celebrarían las fechas republicanas. Como paso previo se constituyó una asociación, la Unión de la Emigración Republicana en Gran Bretaña, a la que se adhirieron 
centenares de refugiados ${ }^{20}$. Las cuotas aportadas, aunque modestas, les permitieron alquilar una casa e iniciar su rehabilitación, en la que se empleó el grupo más capacitado para ello. En el acto de inauguración, aplazado por dificultades de financiación del 14 de abril, como estaba previsto, al 24 de mayo de 1941, Carlos Pérez, presidente de la Unión, informó sobre la labor que se proponían realizar y anunció la celebración de un ciclo de conferencias durante los meses de junio y julio.

El 7 de noviembre, aniversario de la defensa de Madrid, la asociación abrió su sede a los amigos británicos. Allí recibieron también a representantes del Casal Català, del Eusko Etxea, del Hogar Español - "que se estaba formando a prisa en esos días" [p. 238] $]^{21}$ - y a varios miembros de las legaciones diplomáticas acreditadas en Londres. Pérez agradeció la hospitalidad británica, puso la casa a disposición de los visitantes y recordó la responsabilidad de las democracias europeas en la derrota republicana, razón por la que, según afirmó, "Europa había perdido la batalla continental" [p. 240]. Finalmente, quiso destacar también el loable esfuerzo que los emigrados venían realizando ya que "sentían esta guerra como la continuación de la suya ${ }^{22 " ~[p . ~ 240] . ~}$

En efecto, los republicanos españoles llevaban sufriendo los ataques fascistas cinco años consecutivos. El excomisario Rivera pereció en un bombardeo mientras se dirigía a su trabajo. Era el primer entierro de un

${ }^{20}$ El novelista recrea aquí la asociación Españoles, impulsada por iniciativa del exembajador en Londres Pablo de Azcárate. Salazar Chapela fue, además de redactor del prólogo de sus Estatutos (carta de Salazar Chapela a Guillermo de Torre fechada el 26 de marzo de 1942 [ms. 22830-11 (36), Biblioteca Nacional de España, Madrid]), director de la misma, según sostiene Monferrer Catalán (La producción intelectual de los emigrados españoles en Gran Bretaña durante la guerra civil y el franquismo (1936-1975), tesis doctoral inédita, Universitat de Barcelona, 1991, p. 166 y 214).

21 La descripción de esta importante actividad de los exiliados en Londres coincide con la constitución y la inauguración del Hogar Español, al cual Salazar Chapela se halló vinculado durante los primeros meses de su funcionamiento. Probablemente lo abandonó al mismo tiempo que Negrín, quien se dio de baja a principios de 1943 - como documenta Monferrer (La producción intelectual..., ob. cit, p. 225) -, fecha en la que concluye la historia narrada en Perico en Londres. A partir de entonces, ambos trabajaron en la creación del Instituto Español.

22 Sobre la participación de los republicanos en la Segunda Guerra Mundial puede verse el libro de Daniel Arasa, Los españoles de Churchill (Barcelona, Editorial Armonía Poética, 1991,361 p.). 
refugiado en Londres, "que para mayor solemnidad tuvo lugar en medio de un raid, con caer de bombas y sonar estrepitoso de las baterías antiaéreas" [p. 209]. También murieron la práctica totalidad de los empleados y comensales de los restaurantes españoles "Madrid" y "España", adonde solían acudir los refugiados.

Para el teniente coronel Carlos Pérez, éstos seguían siendo soldados de la República, "por su desventura dispersos, pero sin duda prontos a congregarse y alinearse de nuevo en cuanto sonara el clarín" [p. 105]. Sin embargo, no había muestras de que la guerra europea fuera a extenderse a España, a la "España ocupada" [p. 240]. Franco continuaba firme en su postura no beligerante, aunque tampoco neutral. Según Pérez, los fascistas españoles estaban "muy ocupados en vigilar a millones de presos, en luchar con las heroicas guerrillas, en matar..." [p. 198]. Las emisiones radiofónicas de Madrid, Coruña o Málaga les mantenían al corriente de las consecuencias de su victoria. También los ejemplares de $A B C$ que circulaban de mano en mano les mostraban la dureza del régimen. A Perico le producían malestar tanto los artículos como las fotografias, en las que se podían ver guardias civiles vigilando a los obreros que construían una cárcel, las habituales procesiones o un anuncio de Auxilio Social donde aparecía un niño "desnudo, esquelético, una verdadera momia viviente" [p. 123].

Especialmente repugnante le parecía que "un país [...] sin pan ni carbón, aterrorizado por los fusilamientos diarios, con no más horizonte a la vista que el hambre y la muerte" [p. 122], estuviera siendo asediado además por la retórica franquista, "una fraseología superferolítica estúpida" [p. 122] a la que daban apoyo con sus versos - "un chorro [...] de cursilería incoherente" [p. 122] - el conde de Cerdà (Agustín de Foxá) y José María Pelma (José María Pemán), los escritores oficiales. $\mathrm{Y}$ es que, como señalaban repetidamente los refugiados, habían salido de España sus mejores representantes. Por ello, según afirmaba Pucurull (Joan Mascaró) - ex profesor de la Universidad de Barcelona -, "España es hoy [...] una mera expresión geográfica" [p. 49]. En contra de la opinión de algunos de los exiliados, que veían con esperanza la labor intelectual que se había iniciado en Hispanoamérica, Perico afirmaba que la cultura española no podría recuperarse si persistía la diáspora. Que un intelectual prosiguiera su labor fuera no era sino una forma de salvación personal, pero

que este intelectual no se hiciera ilusiones con relación a su patria. Su esfuerzo con ésta sería poco menos que inútil. La 
cultura de su patria iría descendiendo, hundiéndose cuarenta metros diarios hasta hacer pie en el paleolítico [p. 53-54].

\section{El fin de la esperanza}

La firma de la rendición incondicional decretada por Churchill y Roosevelt en Casablanca y la derrota nazi en Stalingrado permiten presumir cuál será el desenlace de la guerra, un final que ya era conocido cuando Salazar Chapela concluyó la redacción de la novela. Sin embargo, buena parte de los emigrados continúa pensando en el próximo regreso. Será Perico quien les advierta finalmente que el destierro va a ser largo, tanto que todos morirán allí, hasta los más jóvenes. En consecuencia, la integración, cada vez más necesaria, resulta además ineludible, como lo demuestra el que los niños vascos educados en Inglaterra cometan faltas de ortografia al escribir en español y que prefieran hablar en inglés entre ellos. Los matrimonios mixtos son también algo corriente, "en los dos últimos meses habían caído cuatro españoles republicanos" [p. 268]. En este sentido debe interpretarse el simbólico final de la novela, en el que Serafin, el hijo de una española con la que Perico convive fraternalmente, se despide para acudir por primera vez a una escuela inglesa.

Perico no es un derrotista, como afirman sus compatriotas, quienes creen que su pesimismo es fruto del desengaño amoroso que ha sufrido al saber que Dora va a casarse con un oficial inglés. Lamentablemente, estaba en lo cierto cuando proclamaba el fin de la esperanza, cuando, como refugiado, adopta una actitud resignada que, en su caso, es idéntica a la que está obligado a tomar en el terreno sentimental. Así, trazando un elocuente paralelismo, se pregunta si el amor por España
habría de ser para algunos como la pasión a veces por la mujer : pasión a distancia, siempre a distancia : la pasión nutrida de zozobra, de frustración y de pena [p. 288].

Concluido su libro, al que llamará finalmente La parrilla española, Perico piensa que tal vez también él, como Palencia, ha elegido la evasión propia de la cabra hispánica, el escape, aunque en su caso a través de la historia. Quizá hubiera sido mejor escribir sobre el presente y el futuro del exilio republicano, al que únicamente le había dedicado las últimas doscientas páginas de su monumental estudio. De haberlo hecho, "habría 
sido algo muy parecido a una novela [...] ¿Quién la escribiría ?" [p. 286], se pregunta. Por de pronto, Perico continúa pensando en su ensayo :

¿Cuándo sus páginas sustanciosas circularían por la Península ? ¿Cuándo ? Obra creada en un clima sumamente propicio (Inglaterra), su Parrilla era intransplantable a climas de dictaduras; obra tramada con la propia urdimbre de los sueños del emigrado, ella misma venía a ser por ahora un emigrado más. En consecuencia, su obra entraría en España cuando pudiera entrar él, sólo entonces... [p. 286]

Obviamente, Perico en Londres no pudo distribuirse ni reseñarse en España. Fue, según confesó su autor a Max Aub, "un libro afortunado y desgraciado $^{23}$ ", porque los dos mil ejemplares de la tirada se vendieron pronto entre Gran Bretaña - adonde no salió finalmente la traducción inglesa a la que el autor se refirió en diferentes ocasiones ${ }^{24}$ - y Buenos Aires, pero no llegó a otros países de América, para lo que hubiera sido necesaria una reedición que nunca se hizo. Salazar Chapela sintió por esta obra una especial predilección, tal vez no sólo por las razones literarias que Alberto Adell presupuso ${ }^{25}$. A ella dedicó y en ella incluyó los primeros años de su propio destierro, cuyo fin no alcanzó a ver. En Perico en Londres vertió también la experiencia vivida por sus compatriotas, sobre los que realizó una deliberada exaltación, guiado tanto por la realidad como por el deseo. Porque, en rigor, la visión del exilio republicano en Gran Bretaña que ofrece

${ }^{23}$ Carta de Salazar Chapela a Max Aub fechada en Londres el 18 de diciembre de 1952 (Fundación Max Aub, Segorbe, Castellón, España).

La correspondencia que mantuvo Salazar Chapela con Guillermo de Torre en los meses previos a la aparición de Perico en Londres recoge varias referencias a la traducción inglesa de la novela - que iba a titularse Spanish Grill -, y deja entrever la posibilidad de que ésta apareciera antes que la edición española. Sin embargo, una entusiasta reseña inglesa de la novela finalizaba expresando el deseo de que Perico en Londres hallara editor inglés (Spanish News Letter, London, 346 (21 st. February 1948), p. 1445-1446).

25 "Era un poco el cariño por el hijo débil, pues no se le ocultaría que, a pesar de todo el trabajo erudito gastado en ella, Perico en Londres sufre del desequilibrio entre el hilo narrativo y la visión, intencionadamente simpática, del ambiente español en Londres, por un lado, y los largos fragmentos de investigación histórica interpolados, por otra" ("Esteban en Londres", Ínsula, Madrid, 221 (abril de 1965), p. 6). 
Salazar Chapela es una amable idealización, una visión personal compatible con el valor testimonial de la obra. Ahí reside precisamente su originalidad. Por todo ello, y aunque en la actualidad contamos con estudios sobre el exilio republicano en Gran Bretaña ${ }^{26}$, sigue vigente la valoración que suscitó su publicación :

Cuando se quiera reconstruir el drama de esta época de persecuciones, de trasplante de seres vivientes de una latitud a otra, con el inevitable desgarramiento que produce en las almas este cambio de paisaje, habrá que recurrir a obras como Perico en Londres, donde con tanto tino psicológico se proyecta el film de los emigrados políticos ${ }^{27}$.

${ }^{26}$ Sobre los primeros años del destierro en el país puede verse el ensayo de Daniel Arasa, Exiliados y enfrentados. Los españoles en Inglaterra de 1936 a 1945 (Barcelona, Llibres de l'Índex (Ediciones de la Tempestad), 1994, 291 p.).

27 Guillermo Díaz Doin, "Esteban Salazar Chapela: Perico en Londres, Editorial Losada, Buenos Aires, 1947", Realidad, Buenos Aires, 9 (mayo-junio de 1948), p. 408. 